\title{
Investigation of various options for processing gray forest soil in a field crop rotation
}

\author{
Victor Balabanov ${ }^{1}$, Afanasiy Lee ${ }^{2 *}$, Begmat Norov $^{2}$, Ibrohim Khudaev $^{2}$, Victor Egorov ${ }^{3}$ \\ ${ }^{1}$ Russian State Agrarian University - Moscow Timiryazev Agricultural Academy, Moscow, Russia \\ ${ }^{2}$ Tashkent Institute of Irrigation and Agricultural Mechanization Engineers, Tashkent, Uzbekistan \\ ${ }^{3}$ Amazon Limited Liability Company, Russia
}

\begin{abstract}
The paper presents the results of studies of various variants of the main treatment of gray forest soil in the experimental field in JSC "Lednevo" of the Yuriev-Polsky district of the Vladimir region Russian Federation. The experiment includes 12 strips, with an average area of 7.5 ha, consisting of 3 variants, with decreasing intensity of tillage and 4 repetitions. Based on the studies, it was found that the main problem associated with the physical condition of the soil was significant compaction of the soil at a depth of $20-25 \mathrm{~cm}$. When using dump processing, increased soil heterogeneity was observed, and with" minimal " variants, the presence of weed vegetation was noted, which required changes in the strategy of using plant protection products and strict compliance with crop rotation. In this paper, it is recommended to remove the "plow sole" and reduce soil compaction by deep loosening of the soil to a depth of $35-40 \mathrm{~cm}$ in autumn, followed by a transition to a minimum soil treatment by cultivators.
\end{abstract}

\section{Introduction}

In the climatic zone of the Vladimir Opolye in the Russian Federation, there is still no significant practical experience and knowledge about less intensive methods of tillage. Only thanks to the knowledge about the nature of the soil and about the climate, over the past 10 years, as a result of extensive demonstration studies, there has been a tangible development in the field of various options for the intensity of cultivation of gray forest soil [1-3].

The transition from a dump to a non-dump tillage system is associated with a variety of technical possibilities for using equipment and with different soils (light, heavy, wet, dry, cold, or warm). In principle, each type of soil and climate zone has its own requirements for the intensity of tillage. The transition from the plow to non-tillage or direct sowing technology has a significant environmental and economic effect. Currently, there is no average or overall optimal tillage intensity. The optimal intensity of tillage is based on the conditions of a certain place of cultivation. The specific nature of the soil, its texture, hydromorphicity, soil structure, humus content, acidity, and climate, i.e., precipitation and temperature, determine the optimal intensity of processing.

\footnotetext{
${ }^{2 *}$ Corresponding author: as lee@mail.ru
} 
The literature and patent analysis showed that obtaining high and stable yields in the production of grain crops largely depends on the quality of sowing. In modern conditions, more and more attention is paid to subsurface-scattered sowing, carried out by seeders for direct sowing, which allows by combining pre-sowing tillage with sowing to achieve the best possible supply of plants in the area of sowing at a given depth with nutrients and moisture [4-8].

The operation of the seeders has shown the feasibility of using pneumatic feeding of seed material on them, which contributes to increasing the width of the seeding unit and increasing its productivity. The working bodies of the seeders are foot coulters, but the existing designs of foot coulters do not fully meet the agrotechnical requirements for sowing. The main disadvantages in their work are a small range of seeds in potashnikova space, insufficient width of a sown strip that leads to a decrease in the uniformity of seed distribution area of the screening at a given depth and requires further improvement of the working bodies for stripe sowing [4-8].

The purpose of the research. Determination of the optimal (minimum) level of the main processing of gray forest soil in the field crop rotation.

\section{Material and Methods}

The climate of the Vladimir region is moderately continental. A distinctive feature of the spring temperature regime is the rapid rise in air temperature. The average monthly air temperature of the warmest month of the year (July) is about $17^{\circ}$. The sum of active daily temperatures above $10^{\circ}$ from the beginning of May to the end of September (125-140 days) is $1900^{\circ}-2200^{\circ}$. Annual precipitation averages from 480 to $580 \mathrm{~mm}$. Up to $75 \%$ of precipitation falls in the warm season and $25-30 \%$ - in the cold. The soils on which the experiment is located are fertile dark-colored carbonaceous and gray forest-related to broad-leaved forests in the Vladimir " opolye» [1-3].

The experiment consists of 12 strips (Figure 1), with an average area of 7.5 hectares, and the experiment occupies a total of 90 hectares. The experiment consists of 3 variants, with decreasing intensity of tillage and 4 repetitions (blocks from A to D). In selected places are lower realized the appraisal of plants and soil (table 1).

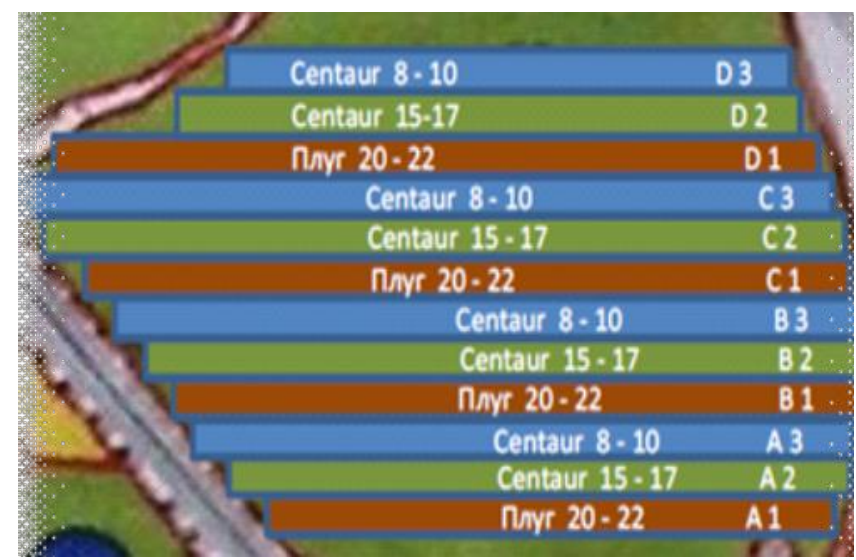

Fig. 1. Scheme of the experiment. Vladimir region, Yuriev- Polsky district, JSC " Lednevo». 
Table 1. Scheme of the experience of JSC "Lednevo»

\begin{tabular}{|c|c|c|c|c|c|c|c|c|c|c|c|c|}
\hline Variants & 1 & 2 & 3 & 4 & 5 & 6 & 7 & 8 & 9 & 10 & 11 & 12 \\
\hline Repetitions & \multicolumn{3}{|c|}{ A } & \multicolumn{3}{|c|}{ B } & \multicolumn{3}{|c|}{$\mathrm{C}$} & \multicolumn{3}{|c|}{ D } \\
\hline Experience & A1 & $\mathrm{A} 2$ & A3 & B1 & B2 & B3 & $\mathrm{C} 1$ & $\mathrm{C} 2$ & $\mathrm{C} 3$ & D1 & $\mathrm{D} 2$ & D3 \\
\hline Technology & 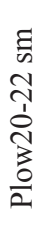 & 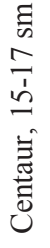 & 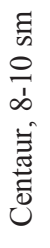 & 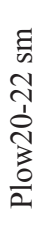 & 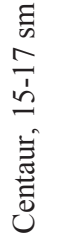 & 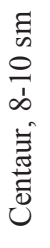 & 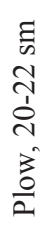 & 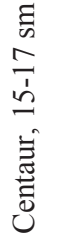 & 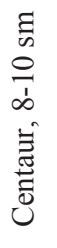 & 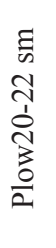 & 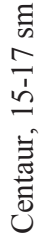 & 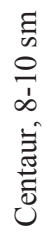 \\
\hline
\end{tabular}

Experience 1 (control). The dump tillage system used in the experimental field includes all the elements that are present in the classical tillage system in the enterprises of the Vladimir region: peeling stubble after harvesting the predecessor to a depth of 5-7 cm, plowing to a depth of $22-25 \mathrm{~cm}$, pre-sowing cultivation to create a seedbed, level the surface of the field and conduct reverse compaction.

Experience 2 (minimum). Non-dump - minimum system of soil treatment. In this processing system, plowing is replaced by cultivation to a depth of 15 to $22 \mathrm{~cm}$. This option is positioned as the nearest alternative to dump tillage. In this case, it is not the turnover of the formation (arable layer) but its mixing. The intensity of soil treatment is reduced.

Experience 3 (minimum). The minimum tillage system. The only difference is that plowing is replaced by cultivation to a depth of $8-10 \mathrm{~cm}$. Accordingly, the intensity of tillage decreases.

Harvesting of grain crops was carried out by the Claas Mega 250 combine harvester.

\section{Results and Discussion}

At the beginning of the experiment (2009), the field was occupied by perennial grasses of 5 years of use. The scheme of the crop rotation of the experimental field is shown in Table 2.

Table 2. Scheme of crop rotation in the experimental field

\begin{tabular}{|c|c|c|c|c|c|c|}
\hline Year & 2006 & 2007 & 2008 & 2009 & 2010 & 2011 \\
\hline Culture & $\begin{array}{c}\text { Perennial } \\
\text { grasses, \% } \\
\text { g. p }\end{array}$ & $\begin{array}{c}\text { Spring } \\
\text { millet }\end{array}$ & $\begin{array}{c}\text { Winter } \\
\text { millet }\end{array}$ & $\begin{array}{c}\text { Oats-Vika } \\
\text { on sea-los }\end{array}$ & $\begin{array}{c}\text { Winter } \\
\text { wheat }\end{array}$ & $\begin{array}{c}\text { Spring } \\
\text { barley }\end{array}$ \\
\hline
\end{tabular}

First of all, the weeds were counted, which revealed a strong infestation with perennial weeds (wheatgrass, sedge).

The soil profile analysis showed that the soil structure in the experimental field is disturbed. There is a clear boundary between the arable and sub-arable layers. There is a "plow sole," formed over many years of working with the plow and the passage of heavy equipment in the field. The strongest seal was found at a depth of $25-30 \mathrm{~cm}$. (figure 2). 


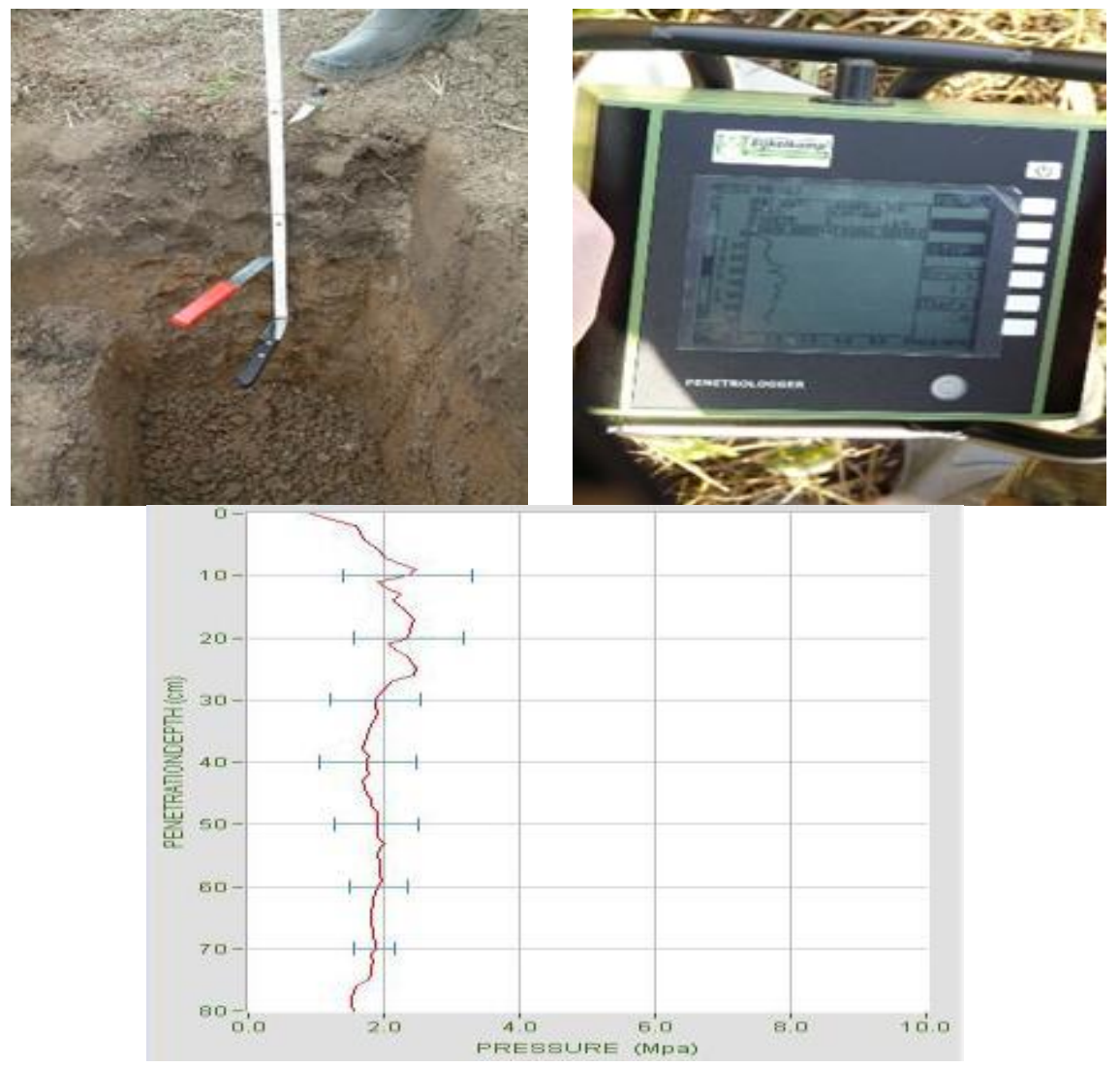

Fig. 2. Soil profile studies

In the spring of 2009, the entire area of the experimental field was sown with a graingrain mixture for silage, with the predominance of the legume component (vetch + oats) in the mixture. Sowing such a mixture can significantly improve the physical condition of the soil. The goal was also pursued, after early harvesting of the mixture for silage, to fight against perennial weeds and engage in cultivation. To destroy negative seals, the soil and plow pan was decided to hold the deep loosening of the entire experimental field at a depth of 35 to $40 \mathrm{~cm}$, chisel type "Paraplu."

In work, an agrochemical analysis was carried out, which revealed a problem with the acidity of the soil (Table 3 ).

Table 3. Agrochemical analysis of soil

\begin{tabular}{|c|c|c|c|c|c|c|c|c|c|c|c|c|}
\hline \multicolumn{13}{|c|}{ Anrochemical soil analysis, Experimental field 09/14/2019 } \\
\hline \multirow{3}{*}{$\mathrm{pH}$} & & & & & & B & $\mathrm{Cu}$ & $\mathrm{Zn}$ & Co & $M n$ & S & $\mathrm{Fe}$ \\
\hline & $\mathrm{P} 205$ & $\mathrm{~K} 2 \mathrm{O}$ & $\mathrm{Ca}$ & $\mathrm{Mg}$ & \multirow{2}{*}{$\begin{array}{l}\text { Organic } \\
\text { matter\% }\end{array}$} & \multirow{2}{*}{$\mathrm{mg} / \mathrm{kg}$} & \multirow{2}{*}{$\mathrm{mg} / \mathrm{kg}$} & \multirow{2}{*}{$\mathrm{mg} / \mathrm{kg}$} & \multirow{2}{*}{$\mathrm{mg} / \mathrm{kg}$} & \multirow{2}{*}{$\mathrm{mg} / \mathrm{kg}$} & \multirow{2}{*}{$\begin{array}{l}\mathrm{mg} / \\
\mathrm{kg} /\end{array}$} & \multirow{2}{*}{$\mathrm{mg} / \mathrm{kg}$} \\
\hline & $\mathrm{mg} / \mathrm{kg}$ & $\mathrm{mg} / \mathrm{kg}$ & $\mathrm{mg} / 100 \mathrm{~g}$ & $\mathrm{mg} / 100 \mathrm{~g}$ & & & & & & & & \\
\hline 5,50 & 126,30 & 77,93 & 10,96 & 5,77 & 4,31 & 0,44 & 3,41 & 0,65 & 1,13 & 14,60 & 10,17 & 58,67 \\
\hline
\end{tabular}

Blocks A, C seeding rate of 500 germinating grains per $\mathrm{m} 2(225 \mathrm{~kg} / \mathrm{ha})$. Blocks B, D the seeding rate is 400 germinating grains per $\mathrm{m} 2(190 \mathrm{~kg} / \mathrm{ha})$. With high-quality soil 
preparation and using band-seeding drills that provide high-quality seedbed preparation, such as Amazone DMC Primera, it is possible to reduce the seeding rate.

It is established that the yield of winter wheat in 2010 on the minimum variants is higher than on the variants with a plow by $0.3-0.45 \mathrm{t} / \mathrm{ha}$. At the same time, the reduction in the seeding rate was also more effective than in the reverse treatment (Table 4).

Table 4. Results of the experiment (2009 - 2010) Culture: Winter wheat - "Moskovskaya 39", 1 reproduction. Predecessor: vetch + oats (removed for silage on 17.07.2009)

\begin{tabular}{|l|c|c|c|c|c|c|}
\hline Variant & $\mathrm{A} 1, \mathrm{C} 1$ & $\mathrm{~B} 1, \mathrm{D} 1$ & $\mathrm{~A} 2, \mathrm{C} 2$ & $\mathrm{~B} 2, \mathrm{D} 2$ & $\mathrm{~A} 3, \mathrm{C} 3$ & $\mathrm{~B} 3, \mathrm{D} 3$ \\
\hline Seeding rate, $\mathrm{w} / \mathrm{m}^{2}$ & 500 & 400 & 500 & 400 & 500 & 400 \\
\hline Yield, $\mathrm{t} / \mathrm{ha}$ & 3.3 & 3.2 & 3.6 & 3.8 & 3.5 & 3.6 \\
\hline
\end{tabular}

First of all, this was due to the quality of tillage, the quality of preparation of the seedbed, and, accordingly, sowing. There was also a problem with soil heterogeneity in the ploughtreated varieties, which was greater than in the "minimal variants". The reason is that the arable horizon in the experimental field is not uniform at a depth of $20-25 \mathrm{~cm}$, and the removal of the infertile layer to the soil surface during plowing for many years gave this picture.

In 2011, the yield of spring barley on non-ploughed varieties treated with a cultivator by $15-17 \mathrm{~cm}$ was also higher by $0.3 \mathrm{t} /$ ha of ploughed variants (Table 5). The yield of the "minimal" variants with a lower intensity of tillage to a depth of $8-10 \mathrm{~cm}$ gave the yield the same as the plowed variants. On the variants with dump treatment, the problem with the heterogeneity of the soil remains, and the main drawback of the "minimal" variants is noted-weeds. Based on this, it is concluded that when.

Table 5. Results of the experiment (2010 - 2011) Culture: Spring barley - "Sonnet," 2 reproduction. Seeding rate: 450 germinating grains per $\mathrm{m} 2(235 \mathrm{~kg} / \mathrm{ha})$. Predecessor: Winter wheat (harvested for grain 30.07. 2010.)

\begin{tabular}{|c|c|c|c|}
\hline Technology & Plow $20-22 \mathrm{~cm}$ & $\begin{array}{c}\text { Cultivator, } \\
17-20 \mathrm{~cm}\end{array}$ & $\begin{array}{c}\text { Cultivator, } \\
15-17 \mathrm{~cm}\end{array}$ \\
\hline Yield, t/ha & 2.5 & 2.8 & 2.4 \\
\hline
\end{tabular}

The refusal of the plow on the gray forest soils of the Vladimir region is possible, but the intensity of the main tillage should be high enough. The magnitude of soil treatment shall not be less than $15-17 \mathrm{~cm}$. The main processing of the soil under spring rape was carried out with some modifications.

The depth of processing on both "minimum" variants was increased by $5-10 \mathrm{~cm}$. This was due to the results of the previous three years of the experiment. Minimal tillage to a depth of 8-10 cm showed a worse result compared to tillage at $15-17 \mathrm{~cm}$. Therefore, it was decided to explore deeper tillage. How deep the processing without turning the reservoir can be, and how it will affect the quality of sowing and yield. As can be seen from Table 6, the yield of spring rapeseed in the experimental field was quite high. The plow and the "minimal" version, processed at $17-20 \mathrm{~cm}$, showed almost the same result of 2.48 and $2.46 \mathrm{t}$ / ha. A variant without a plow is processed at 15-17.

Table 6. Results of the experiment (2011-2012). Culture: Spring rapeseed - "Azorno" - Rapul, F1. Seeding rate: $2.8 \mathrm{~kg} / \mathrm{ha}$. Predecessor: Spring barley (harvested for grain on 25.07.2011.)

\begin{tabular}{|c|c|c|c|}
\hline Technology & Plow $20-22 \mathrm{~cm}$ & $\begin{array}{c}\text { Cultivator, } \\
17-20 \mathrm{~cm}\end{array}$ & $\begin{array}{c}\text { Cultivator, } \\
15-17 \mathrm{~cm}\end{array}$ \\
\hline Yield, $\mathrm{t} / \mathrm{ha}$ & 2.48 & 2.46 & 2.53 \\
\hline
\end{tabular}


In 2010, studies of the agrophysical state of the arable horizon of 10-20-30 cm were carried out in the experimental field.

From Table 7, it is established that the field moisture capacity of arable soil in the experimental field is normal. There were no fundamental differences in this indicator for different tillage options in 2010.

Table 7. Dependence of the field moisture capacity (\%) on the measurement depth (cm) (norm, $35 \%)$

\begin{tabular}{|c|c|c|c|c|c|c|c|c|c|}
\hline Variant & \multicolumn{3}{|c|}{1} & \multicolumn{3}{c|}{2} & \multicolumn{3}{|c|}{3} \\
\hline Depth, cm & 10 & 20 & 30 & 10 & 20 & 30 & 10 & 20 & 30 \\
\hline Humidity, \% & 39.7 & 39.5 & 40.7 & 38.8 & 39.3 & 38.0 & 40.5 & 54.6 & 39.0 \\
\hline
\end{tabular}

With a soil density higher than $1.5 \mathrm{~g} / \mathrm{cm} 3$, there is a possibility of problems with the penetration of plant roots into the depths, and, accordingly, this leads to a decrease in the yield of agricultural crops. The density of the soil, in the minimum variants, gradually increases as the depth of soil cultivation increases. The highest soil density was on the variants without a plow, at a depth of $30 \mathrm{~cm}$ (Table 8).

Table 8. Dependence of soil density $\left(\mathrm{g} / \mathrm{sm}^{3}\right)$ on the depth of measurement (sm) (norm $15 \mathrm{~g} / \mathrm{sm}^{3}$ )

\begin{tabular}{|c|c|c|c|c|c|c|c|c|c|}
\hline Variant & \multicolumn{3}{|c|}{1} & \multicolumn{3}{|c|}{2} & \multicolumn{3}{|c|}{3} \\
\hline Depth, cm & 10 & 20 & 30 & 10 & 20 & 30 & 10 & 20 & 30 \\
\hline Soil density, (g/ cm3) & 1.25 & 1.30 & 1.26 & 1.19 & 1.37 & 1.40 & 1.27 & 1.37 & 1.47 \\
\hline
\end{tabular}

Despite this, the soil density index did not exceed the permissible limit.

The pore volume or porosity of the soil is the most important agrophysical characteristic, depending on the soil's mechanical composition and moisture content. In natural conditions, especially in the humid, i.e., humid zone, which includes all areas covered with forests, soils always contain air and moisture in the pores. The amount of moisture that the soil can retain and which plants and microorganisms use for a long time is determined by the structure of the pore space, i.e., the ratio of pores of different sizes within the soil.

From the point of view of agrophysical and water-physical properties, the soil of optimal mechanical composition (light or medium loam) and optimal density (1.1 - 1.3 $\mathrm{g} / \mathrm{sm}^{3}$ ) should be considered "good." The porosity reaches $45-55 \%$ with a satisfactory structure of the pore space and a high water retention capacity (Table 9).

Table 9. Dependence of the total pore volume (\%) on the measurement depth (cm) (norm $38 \%$ )

\begin{tabular}{|c|c|c|c|c|c|c|c|c|c|}
\hline Variant & \multicolumn{3}{|c|}{1} & \multicolumn{3}{c|}{2} & \multicolumn{3}{c|}{3} \\
\hline Depth, cm & 10 & 20 & 30 & 10 & 20 & 30 & 10 & 20 & 30 \\
\hline $\begin{array}{c}\text { Total pore } \\
\text { volume (\%) }\end{array}$ & 52.91 & 51.06 & 52.38 & 54.98 & 48.38 & 47.09 & 52.19 & 48.49 & 44.49 \\
\hline
\end{tabular}

Soil air is a source of carbon dioxide for plants used in photosynthesis. From 38 to $72 \%$ of the total amount of $\mathrm{CO}_{2}$ used to build the crop comes to the plant from the soil. Noncapillary air capacity, i.e., the air capacity of interaggregate pores, cracks, and chambers, is essential for ensuring normal soil aeration. It includes large pores, interstructural cavities, root, and worm passages in the soil thickness and is mainly associated with free soil air. Non-capillary air capacity with the lowest moisture capacity is of particular importance for aeration. If the air capacity at the lowest moisture capacity is less than $15 \%$, then the soil aeration is insufficient to ensure a favorable composition of soil air. 
The amount of non-capillary air for all variants of the intensity of tillage has a fairly low indicator. First of all, there are options without a plow. A decrease in the volume of noncapillary air is observed with increasing depth (tab 10).

Table 10. Dependence of non-capillary air capacity ( $\%)$ on the depth of the measurement (sm) (norm $15 \%)$

\begin{tabular}{|c|c|c|c|c|c|c|c|c|c|}
\hline Variant & \multicolumn{3}{|c|}{1} & \multicolumn{3}{|c|}{2} & \multicolumn{3}{|c|}{3} \\
\hline Depth, sm & 10 & 20 & 30 & 10 & 20 & 30 & 10 & 20 & 30 \\
\hline $\begin{array}{c}\text { Non-capillary } \\
\text { air capacity, (\%) }\end{array}$ & 13.21 & 11.56 & 11.68 & 16.18 & 9.08 & 9.09 & 11.69 & 6.00 & 5.49 \\
\hline
\end{tabular}

Hardness is an important agricultural indicator that characterizes soils' physical and mechanical properties, more precisely, the resistance of the soil to root growth, or the resistance of the soil that needs to be overcome by the tillage working body during its processing. When using dump plows, a "plow sole" is formed, which prevents the penetration of moisture from precipitation into the lower layers. This, in turn, contributes to the development of water erosion on the slope lands, and on the plains, and in the lowlands - the formation of wet "saucers" in which melt and rainwater stagnate. The resistance of 1.5 $\mathrm{MPa}$ can be considered as the upper edge of the normal growth of the root system of plants. This pressure is provided by the root system of many types of agricultural plants (Figure 3).

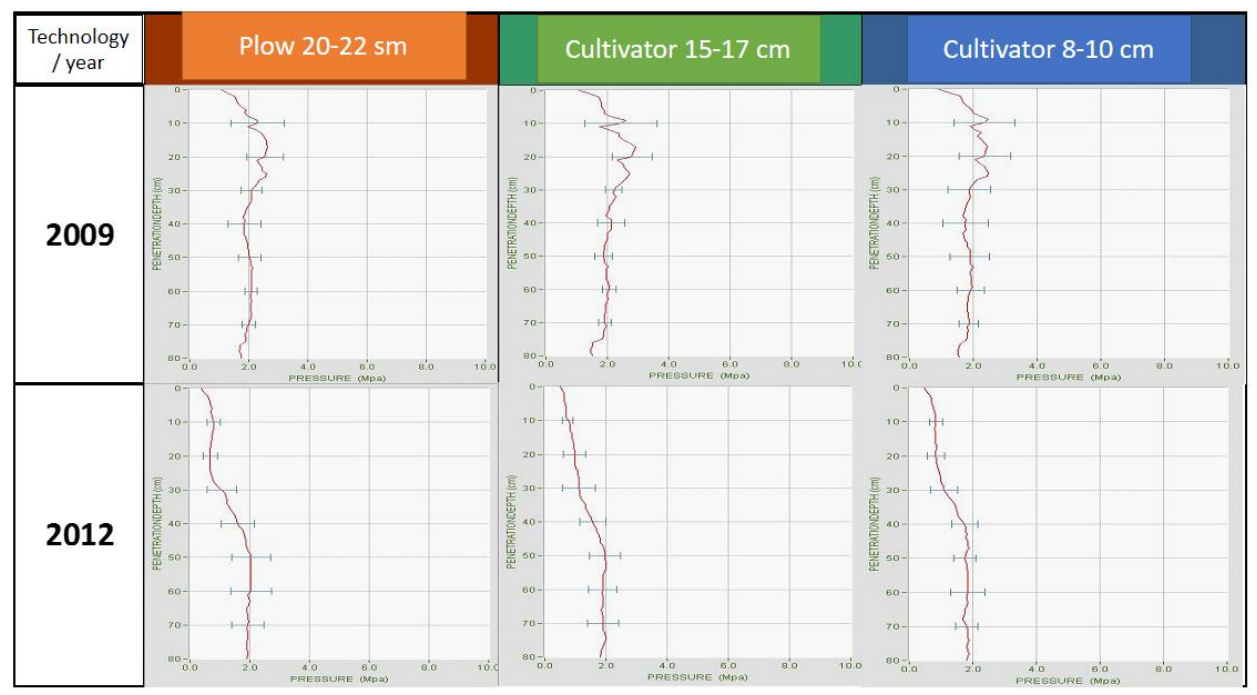

Fig. 3. Resistance (hardness) soils (MPa)

In order to improve the quality of sowing grain crops with pneumatic seeders, a new design of a coulter for strip sowing has been developed (Patent 124526) (Figure 4). 

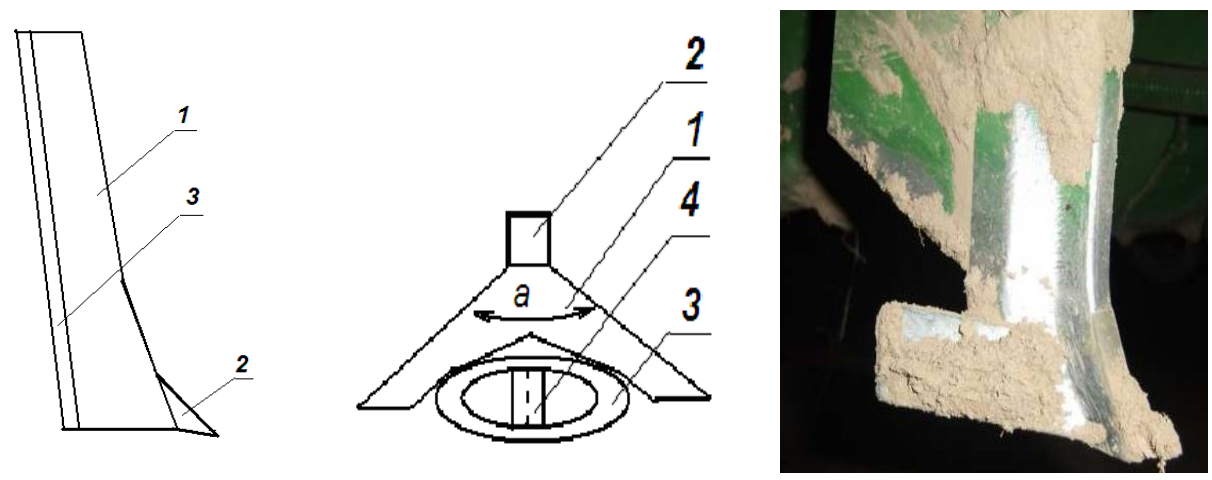

Fig. 4. Coulter for strip seeding (Patent 124526) [9-10] 1 is stand; 2 is sock-naralnik; 3 is vas deferens, 4-partition-distributor

When driving planter opener with stand 1, attached to the lower part of the Shoe having a wedge-shaped Breasts and sock-naralnik 2, and on the rear surface of the VAS deferens 3, with the drive mechanism seeders deepens in the ground and has to move forward, opening Bo-Rosu. When working planter seed material is supplied sowing APPA-Rath, the VAS deferens into the lower elliptical part, where the flow is divided by the vertex of a triangular partition-way valve 4 into two equal parts, which are directed on opposite sides of a triangular partitions-rail. Due to the fact that the ellipse is oriented with its large axis across the axis of movement of the coulter, most of the seeds are sown on the left and right sides, and a small proportion of seeds fall into the nose part due to the shading of the seed distributor. Thus, the entire flow of seeds is distributed at the bottom of the furrow into two rows, ensuring the absence of seeds in the problematic, from the point of view of embedding, area under.

Seeds at the bottom of the furrow are covered with soil with a special zagartach or disks installed behind the coulter [9-14].

Wedge-shaped rack and Shoe opener, and the presence of ellip-conformable of the VAS deferens with a triangular partition allocator, POS-vasut to improve the quality loosening of the soil, the uniformity of distribution and seeding, and, consequently, their germination, reduce energy costs when sowing, due to the wedging action opener for SMOS-Woo, and reduce the deterioration of structural elements of the Shoe, due to the reduction of the contact angle of the surface of the vomer with the soil.

The design of the coulter (Patent 124526) for combined strip sowing units was awarded a diploma and a bronze medal for participation in the competition "For the production of highly efficient agricultural technology and the introduction of advanced resource-saving technologies," in the nomination "Tillage and Sowing machines" at the 16th Russian AgroIndustrial exhibition "Golden Autumn-2014" (VDNH, 2014y).

\section{Conclusions}

1. As a result of the research, it was found that the main problem associated with the physical condition of the soil at the experimental field in JSC "Lednevo" in the YurievPolsky district of the Vladimir region was significant compaction of the soil at a depth of $20-25 \mathrm{~cm}$. When using the dump treatment, increased soil heterogeneity was observed, and in the "minimal" variants, the presence of weeds was noted, which required a change in the strategy of using plant protection products and strict compliance with crop rotation. 
2. Based on the conducted research in the Vladimir Opolya region, to remove the plow sole and reduce soil compaction, deep loosening of the soil to a depth of $35-40 \mathrm{~cm}$ is recommended in autumn, followed by a transition to minimal tillage by cultivators to a depth of 15-17 cm with strip sowing of grain with pneumatic seeders, which increases the yield of winter wheat, spring barley and spring rapeseed by $0.3-0.45 \mathrm{t} / \mathrm{ha}$. At the same time, there is a decrease in economic costs by 261-290 r/ha when using non-dump treatment.

\section{References}

1. Taleeva DA Efficiency of basic processing techniques in optimizing the fertility of gray forest soil in the cultivation of barley in the conditions of the Vladimir opol'e / Darina Aleksandrovna Taleeva, author. diss. cand. s.-kh. sciences. M., RSAUMoscow Agricultural Academy named after K.A. Timiryazeva, (2013).

2. Egorov, V.V. The use of resource-saving technologies for soil processing in the conditions of Vladimirsky opolye / A.A. Mosienko, V.I. Balabanov, Egorov V.V. // International technical and economic journal. No. 1, (2013).

3. Egorov, V.V. Experience in the use of resource-saving technologies in soil processing / V.I. Balabanov, V.V. Egorov, A.A. Mosienko // Reports of TSKhA: Collection of articles. Issue 285. Part I. -M.: RGAU-MSKhA. (2013).

4. Balabanov V.I., Buksman V.V., Egorov V.V. Application of agricultural machinery "Amazone" in coordinate farming // In the collection: Innovative technologies in science and education. Proceedings of the VI International Scientific and Practical Conference. (2018)

5. Balabanov V.I. Field strategy. Implementation of innovations in coordinate farming. Agricultural engineering and technology. No. 5. -P. 50-53. . (2016).

6. Balabanov V.I. Navigation technologies in agriculture. Coordinate agriculture / IN AND. Balabanov, S.V. Zhelezova, E.V. Berezovsky, A.I. Belenkov, V.V. Egorov. M.: From the RSAU-Moscow Agricultural Academy them. K.A. Timiryazeva. -143 p. (2013).

7. Balabanov V.I. Research trends in precision farming / Agrotechnology. 2017. T. 6. №4. -P. 101.

8. Balabanov V.I. Development of new elements of precision farming systems based on precision farming centre of Russian state agrarian university - Moscow agricultural academy named after K. A. Timiryazev // World Journal of Agriculture and Soil Science. -T. 1. No 1. -P. 2. (2018).

9. Egorov, V.V. Opener for direct sowing of agricultural crops [Text] / V.I. Balabanov, V.V. Egorov, A.A. Dray // Feed production. No. 8. -P. 46-49.(2015).

10. Patent 124526 Russian Federation, IPC A01C7 / 20. Opener for direct strip seeding / Balabanov V.I., Berezovsky E.V., Egorov V.V. (RU); applicant and patentee Balabanov V.I., Berezovsky E.V., Egorov V.V. (RU) -No. 2012127875 applied. publ. from 10.02.2013 Bul. No. 4. -3 p. (2012).

11. Muratov, A., Muratov, O., Melikuziyev, S.Operational control of energy consumptions of reclamation machines IOP Conference Series: Earth and Environmental Science, 614 (1). DOI: 10.1088/1755-1315/614/1/012042. (2020).

12. Arifjanov, A., Rakhimov, K., Abduraimova, D., Babaev, A., Melikuziyev, S. Hydrotransport of river sediments in hydroelelators. IOP Conference Series: Materials Science and Engineering, 869 (7). DOI: 10.1088/1757-899X/869/7/072003. (2020). 
13. Muratov, A., Melikuziev, S. Technology of formation of combined products of meliorative purpose IOP Conference Series: Materials Science and Engineering, 883 (1). DOI: 10.1088/1757-899X/883/1/012060.(2020).

14. Lee, A., Usmonov, T., Norov, B., Melikuziev, S.Advanced device for cleaning drain wells IOP Conference Series: Materials Science and Engineering, 883 (1).DOI: 10.1088/1757-899X/883/1/012181. (2020). 